\title{
Variants of PGIS and PPAR $y$ in Idiopathic Pulmonary Arterial Hypertension
}

\author{
Shivani Vadapalli ${ }^{1}$, Chaitra KL${ }^{1}$, Satyanarayana $\mathrm{ML}^{1}$, Surekha Rani $\mathrm{H}^{1}$, Sastry BKS ${ }^{2}$ and Pratibha Nallari ${ }^{1 *}$ \\ ${ }^{1}$ Department of Biology, Delhi University, Delhi \\ ${ }^{2}$ Department of Biochemistry, Delhi University, Delhi
}

\begin{abstract}
Introduction: Idiopathic Pulmonary Arterial Hypertension (IPAH) is a subset of a heterogeneous group of diseases called Pulmonary Arterial Hypertension (PAH), characterized by elevated pulmonary arterial pressure (PAP) and is associated with severe arteriopathy, vascular lesions, and right heart failure. The role of prostacyclin synthase, an enzyme responsible for production of prostacyclin, and peroxisome proliferator-activated receptor gamma, involved in many cellular activities, is studied here.

Objectives: The objective of the study is to determine any association of prostacyclin synthase and Peroxisome proliferator-activated receptor gamma with Idiopathic Pulmonary Arterial Hypertension

Materials and methods: A total of 77 IPAH patients and 100 controls were genotyped using PCR SSCP and RFLP, and appropriate statistical tests were employed to determine the significance and to interpret the results.

Results and conclusion: This study has attempted to correlate promoter/gene polymorphisms of $P G I S$ to its activity, and it can be concluded that the VNTR polymorphism and the polymorphism found in exon 6 may not have an effect on the levels of PGIS. The alanine variant of P12A polymorphism of PPARy was found to be significantly associated with a reduced risk of IPAH.
\end{abstract}

\section{Keywords: IPAH; PGIS; PPAR $\gamma$}

\section{Introduction}

Idiopathic Pulmonary Arterial Hypertension (IPAH) is a subset of a heterogeneous group of diseases called Pulmonary Arterial Hypertension (PAH), characterized by elevated pulmonary arterial pressure (PAP); $25 \mathrm{~mm} \mathrm{Hg}$ at rest and $30 \mathrm{~mm} \mathrm{Hg}$ during exercise, which is much higher than a normal PAP of $14-18 \mathrm{~mm} \mathrm{Hg}$ at rest. IPAH is associated with severe arteriopathy, vascular lesions, and right heart failure. Of the many pathways being implicated, the prostacyclin pathway is one such involved in the etiopathogenesis of IPAH [13]. Moncada et al [4] discovered prostacyclin, as the most actively produced lipid in endothelial cells and as a product of arachidonic acid in all vascular tissues. Prostacyclin is a mediator involved in complex interactions of the vessel wall, blood flow and platelet function and it appears to be a protective factor against excessive vasoconstriction, platelet deposition and cellular proliferation in the vascular tissues $[5,6]$. Prostacyclin was developed as a therapeutic target in IPAH, in view of its many haemodynamic effects $[7,8]$.

Prostacyclin Synthase is essential in the production of prostacyclin from prostaglandin and aberrant expression PGIS has been recorded in patients with IPAH. A 183-bp region in the 5'UTR contains a previously reported 9-bp variable-number tandem repeat (VNTR), CCGCCAGCC, housing Sp1-consensus-sequence motifs, that determines the promoter activity. The allele with four repeats (R4) contains three putative Sp1-binding sites, and the R6 allele contains five Sp1-binding sites. The R6T allele, a mutated repeat, contains only four Sp1-binding sites, as does the R5 allele. The rare R3 allele has with only two Sp1 binding sites [9]. Due to its potential role in IPAH, screening of PGIS was taken up.

Peroxisome proliferator-activated receptors (PPAR), members of a nuclear hormone receptor/transcription factor superfamily, are known to have anti-inflammatory properties [10-12]. PPAR has been found to regulate vascular smooth cell migration and proliferation. Potential roles of PPAR $\gamma$ may include tumor suppression, angiogenesis, and apoptosis induction [13-15]. Recently, PPAR $\gamma$ has also been shown to have an anti-apoptotic effect in the presence of its agonist rosiglitazone, using Bcl-2 as an intermediary [16].

Patients with IPAH have reduced pulmonary mRNA expression of PPAR $\gamma$ [17]. Interleukin-6 [18], fractalkine [19], monocyte chemoattractantprotein-1[20] and endothelin-1 (ET-1) [21], circulating factors found to be associated with insulin resistance are normally repressed by PPAR $\gamma$. Thus, it has been proposed that insulin resistance may be a factor in IPAH [22] with a $\mathrm{C}>\mathrm{G}$ substitution in PPAR 2 exon $\mathrm{B}$ resulting in a Proline to Alanine substitution in codon 12 (P12A; rs1801282), which has been found to modulate the transcriptional activity of the gene in vitro [23]. The P12 allele of PPAR2 gene is implicated as risk allele for insulin resistance [24]. Reports have also shown that prostacyclin and its analogs such as iloprost are ligands for PPAR, which subsequently activate these receptors [25]. Thus in the present study the association of PGIS and PPAR- $\gamma 2$ gene polymorphisms with IPAH was evaluated.

\section{Materials and Methods}

The study was approved by the Ethics Committee of Care Hospitals, Hyderabad. The patients included in the study were confirmed IPAH cases, referred by the cardiologist. The study included, 77 IPAH patients

*Corresponding author: Pratibha Nallari, Department of Biology, Delhi University, India, Tel: 91888548 6499; E-mail: prathinallari@yahoo.com

Received September 09, 2015; Accepted October 06, 2015; Published October 12, 2015

Citation: Vadapalli S, Chaitra KL, Satyanarayana ML, Surekha Rani H, Sastry BKS, et al. (2015) Variants of PGIS and PPARy in Idiopathic Pulmonary Arterial Hypertension. J Clin Med Genomics 3: 130. doi: 10.4172/2472-128X.1000130

Copyright: (c 2015 Vadapalli S, et al. This is an open-access article distributed under the terms of the Creative Commons Attribution License, which permits unrestricted use, distribution, and reproduction in any medium, provided the original author and source are credited. 
Citation: Vadapalli S, Chaitra KL, Satyanarayana ML, Surekha Rani H, Sastry BKS, et al. (2015) Variants of PGIS and PPARy in Idiopathic Pulmonary Arterial Hypertension. J Clin Med Genomics 3: 130. doi: 10.4172/2472-128X.1000130

Page 2 of 5

(73 IPAH and 5 Familial PAH) and 100 randomly selected healthy subjects without history of cardiac and systemic disorders.

\section{Molecular analyses}

DNA was isolated followed by Polymerase Chain Reaction (PCR) amplification using specific primers. PCR assays was carried out in a $25 \mu \mathrm{l}$ volume tube with $100 \mathrm{ng}$ of genomic DNA, $10 \mathrm{pM}$ of each primer, $2.0 \mathrm{mM}$ dNTP (Merck, Germany), $1.5 \mathrm{mM} \mathrm{MgCl}_{2}$ and 10x PCR buffer [50 mM $\mathrm{KCl}, 500 \mathrm{mMTris}$ buffer, $160 \mathrm{mM}\left(\mathrm{NH}_{4}\right)_{2} \mathrm{SO}_{4}, \mathrm{pH} 8.8$, and $0.1 \%$ Tween 20 ], $0.1 \%$ Triton X-100 and $0.5 \mathrm{U}$ Taq polymerase (Invitrogen). The thermal cycling was carried out in Eppendorf Gradient Thermal cycler (Germany).

The 9 bp VNTR polymorphism in the 5'-flanking region of the promoter of the human prostacyclin synthase gene was determined by nested PCR [26]. Two sets of primer sequences were used to amplify $1530 \mathrm{bp}$ fragment, encompassing the GC rich 5'-flanking region and exon 1 of the PTGIS gene by PCR with the sense primer P AF (from positions -1431 to -1410 , the position of the ATG translation start site being referred to as +1 ) and the antisense primer $\mathrm{P}$ BR (from position +84 to +99 ). In a second step, the PCR product was used as a template to amplify a 216-bp fragment, containing the proximal promoter region and exon 1, with primers P BF (from positions -117 to -100) and P BR.

Single Stranded Confirmation Polymorphism (SSCP) was carried out for PGIS as per Orita et al [27] protocol. The PCR products were denatured at $95^{\circ} \mathrm{C}$ for 10 minutes, quenched in ice for 5 minutes and then loaded on $11 \%$ native polyacrylamide gels with $150 \mathrm{~V}$ at room temperature. The gels were visualized by silver staining. The samples exhibiting aberrant band pattern were sequenced commercially.

PCR-RFLP technique was adopted for genotyping of the PPAR 2 P12A allele. The $\mathbf{1 5 4} \mathbf{b p}$ amplified product was digested with HhaI restriction enzyme (New England Biolabs,USA). Digested samples were separated on $10 \%$ non-denaturing polyacrylamide gel and visualized by silver staining. The genotypes identified are CC / P12P (158 bp), CG/ P12 A (154/132/ 22 bp), and GG/A12A (132/22 bp) respectively. The primers used for the study are given in Table 1 along with their annealing

\begin{tabular}{|l|l|l|c|}
\hline Exons & \multicolumn{1}{|c|}{ Primer sequences } & Annealing Temp $\left({ }^{\circ} \mathrm{C}\right)$ \\
\hline $\mathbf{1} *$ & $\begin{array}{l}\text { PAF : GGGTCAGGCAGGTAAAGGTGAG } \\
\text { P BF: AAAGCGGGCTGGGTGGG } \\
\text { P BR: GGGCCGAGCGGAGCAG }\end{array}$ & $\mathbf{5 4 . 6}$ \\
\hline $\mathbf{2}$ & $\begin{array}{l}\text { F: GACAAGTGCCATGGCTTCTG } \\
\text { R: CCGAGGCACAAGAGGCAC }\end{array}$ & $\mathbf{5 8 . 4}$ \\
\hline $\mathbf{3}$ & $\begin{array}{l}\text { F: TATCCCTGGCAACTTCCCAC } \\
\text { R: GTGCCATCTCCAGCCACTC }\end{array}$ & $\mathbf{5 3 . 7}$ \\
\hline $\mathbf{4}$ & $\begin{array}{l}\text { F: ATGCTTTGTTTCCTGCCTC } \\
\text { R: GGGGGCTGCACAGCCTC }\end{array}$ & $\mathbf{5 1 . 7}$ \\
\hline $\mathbf{5}$ & $\begin{array}{l}\text { F: GACACATGAGTGTCCCAGG } \\
\text { R: TGGGGCCCATGGTGC }\end{array}$ & $\mathbf{6 0 . 1}$ \\
\hline $\mathbf{6}$ & $\begin{array}{l}\text { F: TCTCTGTGCTCTGTCCTGC } \\
\text { R: CCACTTGCACATTCACACCC }\end{array}$ & $\mathbf{5 5 . 6}$ \\
\hline $\mathbf{7}$ & $\begin{array}{l}\text { F: ACAGGGGCCCTTCTCTTGC } \\
\text { R: GAGGGTCTGAACGAGTCTC }\end{array}$ & $\mathbf{5 3 . 7}$ \\
\hline $\mathbf{8}$ & $\begin{array}{l}\text { F: CTTGCACCTGCCCCATGC } \\
\text { R: CGGTCACCACGTCGCAG }\end{array}$ & $\mathbf{5 7 . 6}$ \\
\hline $\mathbf{8 b}$ & $\begin{array}{l}\text { F: GGCAGACGGGAGAGAATTC } \\
\text { R: GACCAGGCGCCCTGCC }\end{array}$ & $\mathbf{5 8 . 4}$ \\
\hline $\mathbf{9}$ & $\begin{array}{l}\text { F: TCAGAAAGGACCTTCTTCC } \\
\text { R: CCCTGGCCCCCACTC }\end{array}$ & $\mathbf{5 4 . 6}$ \\
\hline $\mathbf{1 0}$ & $\begin{array}{l}\text { F: TTACCATGCCATCTCTCTGC } \\
\text { R: AGAAAGCTGGGGGCTGGG }\end{array}$ & $\mathbf{5 7 . 1}$ \\
\hline PPAR & *12A & $\begin{array}{l}\text { F: TCTGGGAGATTCTCCTATTGGC } \\
\text { R: CTGGAGACAACTACAAGAG }\end{array}$ & $\mathbf{5 2 . 0}$ \\
\hline
\end{tabular}

Table 1: Primer sequences used for PCR amplification of PGIS and PPARY. temperatures. To account for any discrepancies brought about by the use of Taq polymerase, the experiments were performed in triplicate.

Deviations from the Hardy-Weinberg equilibrium were tested for the polymorphisms in cases and controls by comparing observed and expected genotype frequencies by carrying out the exact goodness of fit test. Odds ratios, with $95 \%$ confidence intervals were calculated to compare allele and genotype frequencies. Secondary structure of the protein was predicted in case of PGIS enzyme to determine any changes caused by the mutation detected. HAPMAP data was compared to correlate the frequencies obtained worldwide.

\section{Results}

\section{PGIS}

The sequence immediately upstream from the translational initiation site of the human PGIS gene has GC-rich and pyrimidinerich regions. This region consists of a number of repeats of the 9-bp nonamer sequence (CCGCCAGCC) varying from 3 to 7 copy numbers. Screening of this region was carried out.

Table 2 gives the frequency distribution of VNTR alleles of PGIS gene. The most frequent allele observed is the R6T allele (81\%), followed by the wild-type allele R4 (10.0\%) and the R6 allele (6\%), whereas the R5 allele was least common with a frequency of only $3.0 \%$. In patient group the frequency of R4, R5, R6 and R6T was observed to be $12.9 \%, 3.8 \%, 5.1 \%$ and $77.9 \%$, respectively (Table 2).Interestingly, the two rare alleles R3 and R7 were not observed either in controls or IPAH patients of Indian cohort, but reported elsewhere, pointing to the diversity of the Indian population.

SSCP analysis of exon 6 of PGIS revealed two types of band patterns (A and $\mathrm{B}$ ), in both the controls and patients. The band pattern A and $\mathrm{B}$ was observed with a frequency of $73 \%$ and $27 \%$ in controls in comparison to $77.9 \%$ and $22.1 \%$ in IPAH patients. The electropherogram of the two band patterns are shown in Figures $1 \mathrm{~A}$ and B.

\begin{tabular}{|l|c|c|c|c|c|c|c|c|}
\hline \multirow{2}{*}{} & \multicolumn{2}{|c|}{ R4 } & \multicolumn{2}{c|}{ R5 } & \multicolumn{2}{c|}{ R6 } & \multicolumn{2}{c|}{ R6T } \\
\cline { 2 - 9 } & $\mathbf{N}$ & \% & N & \% & $\mathbf{n}$ & $\%$ & $\mathbf{n}$ & $\%$ \\
\hline Controls & 20 & 10 & 6 & 3 & 12 & 6 & $\mathbf{1 6 2}$ & $\mathbf{8 1}$ \\
\hline IPAH & 20 & 12.9 & 6 & 3.8 & 8 & 5.2 & $\mathbf{1 2 0}$ & $\mathbf{7 7 . 9}$ \\
\hline
\end{tabular}

Table 2: Frequency distribution of VNTR alleles of PGIS gene.
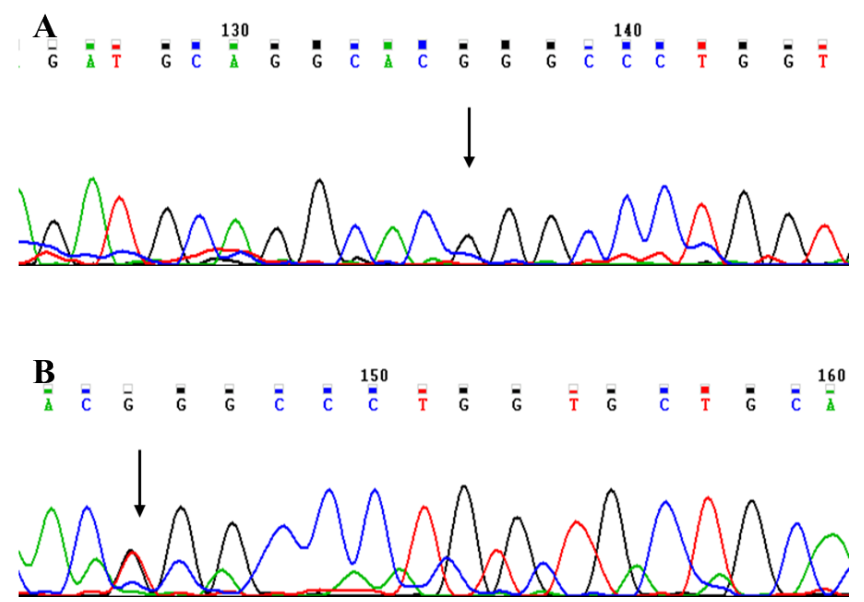

Figure 1: A) Electropherogram of Band pattern A showing "GG" genotype; B) Electropherogram of Band Pattern B showing the heterozygote "GT" genotype. 
Citation: Vadapalli S, Chaitra KL, Satyanarayana ML, Surekha Rani H, Sastry BKS, et al. (2015) Variants of PGIS and PPARy in Idiopathic Pulmonary Arterial Hypertension. J Clin Med Genomics 3: 130. doi: 10.4172/2472-128X.1000130

Page 3 of 5

On sequencing a $\mathrm{G}>\mathrm{T}$ transversion was observed in band pattern B. The sequence was then subjected to NCBI BLAST. Blast of pattern- B (genotype $\mathrm{G} / \mathrm{T}$ ) revealed a $\mathrm{G}>\mathrm{T}$ transversion at 18336700 of the exon 6 (ref sequence: NT_011362.10, chromosome 20 contig assembly). The change lies in the second base of the $275^{\text {th }}$ codon (c. $824 \mathrm{G}>\mathrm{T}$ ). Translation of sequence with $\mathrm{T}$ at $\mathrm{c} .824$ revealed the presence of Leucine (L) at amino acid position 275; instead of Arginine (R). This is a novel non- synonymous polymorphism (R275L). Since arginine is a basic polar amino acid and leucine is a neutral non-polar amino acid, it is likely that this change affects the structure of the protein due to polarity changes.

Probable structure of $275^{\text {th }}$ amino acid region: Secondary structure prediction software using PSIPRED prediction revealed the structure shown in Figure 2. This software predicted that 270 to 278 amino acids to be part of helix. Therefore further studies are required in order to conclusively determine the role of this non-synonymous SNP in PGIS structure and function.

In comparison to rest of the known missense polymorphisms of PGIS, the frequency of R275L polymorphism was observed to be very high $(27 \%)$ in controls and patients $(22.5 \%)$.

A comparison of the clinical profile of IPAH patients with R275L polymorphism in comparison to IPAH patients with R275R revealed no significant difference and presentation of symptoms among the two patient groups showed an increased frequency of angina and presyncope in patients with R275L polymorphism.

SSCP analyses of exons $2,3,4,5,7,8 \mathrm{a}, 8 \mathrm{~b}, 9$ and 10 did not show any band pattern variations, indicating the conserved nature of these exons, in the study cohort.

\section{PPAR- $\gamma 2$}

Following PCR amplification and restriction digestion of exon 12 of $P P A R-\gamma 2$, the genotypes were identified as CC / P12P (158 bp), CG/ P12 A (154/132/ $22 \mathrm{bp})$, and GG/A12A (132/22 bp) as shown in Figure 3.

The genotype and allelic frequencies of PPAR $y 2$ P12 A polymorphism is given in Table 3 . The CC genotype (which codes for

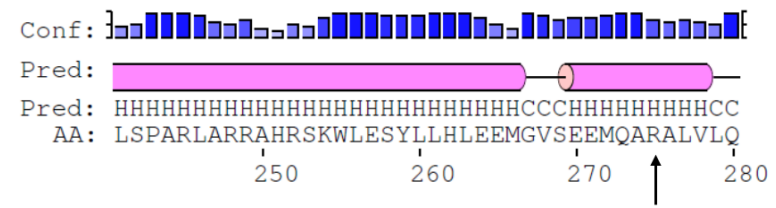

Figure 2: Secondary structure of the PGIS protein predicting that 270 to 278 amino acids may be part of helix.

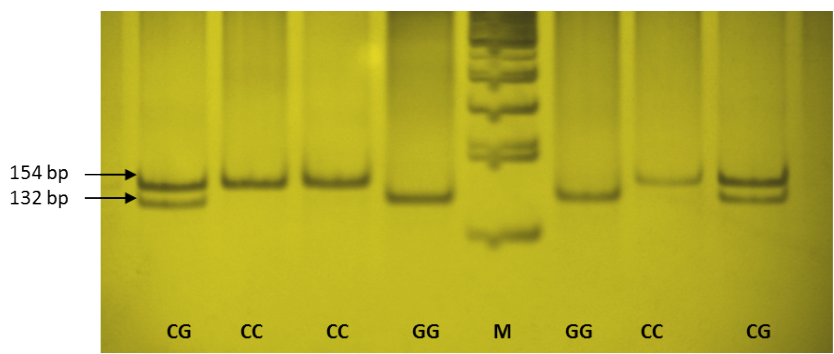

Figure 3: Genotypes of PPAR $\gamma 2$ P12A polymorphisms after restriction digestion with $\mathrm{Hhal}$ restriction enzyme.
Proline) was the predominant genotype in both controls (69\%) and IPAH group (85.7\%), with the frequency being much higher in the latter group. The frequency of $\mathrm{C} / \mathrm{G}$ genotype was observed to be $27 \%$ in controls and $14.2 \%$ in patients. Interestingly the G/G genotype (which codes for Alanine) was completely absent in patient group and seen only in $4 \%$ of controls. The allelic frequencies of $\mathrm{C}$ and $\mathrm{G}$ allele were observed to be 0.83 and 0.18 in controls and 0.93 and 0.07 in patients, respectively. Different ethnic populations have varied allelic frequencies for the Alanine variant. The GG genotype is in general a very rare, as evident from the Hapmap data (Figure 4).

Table 4 gives the odds risk estimates of the P12A polymorphism in IPAH patients in comparison to the controls. The CC genotype, i.e., homozygosity of Proline was found to be associated with an increased risk for IPAH (OR-2.35, CI; 1.08-5.11). The heterozygous (CG genotype), was found to be protective in nature (p-0.0074).Based on the dominant model, the combination of CG+GG genotypes were observed to be associated with reduced risk to IPAH (p-0.0072) compared to the CC genotype, further strengthening the protection conferred by CG genotype. Thus the Alanine variant was found to be a protective allele against IPAH.

\begin{tabular}{|l|c|c|c|c|}
\hline Genotype Frequency & \multicolumn{2}{c|}{} \\
\hline & \multicolumn{3}{|c|}{ Controls } & \multicolumn{2}{c|}{ IPAH } \\
\hline CC & N & $\%$ & $\mathbf{n}$ & $\%$ \\
\hline CG & $\mathbf{6 9}$ & $\mathbf{6 9}$ & $\mathbf{6 6}$ & $\mathbf{8 5 . 7}$ \\
\hline GG & 27 & 27 & 11 & 14.2 \\
\hline Allele Frequency & 4 & 4 & - & - \\
\hline C & & & & \\
\hline G & 0.83 & \multicolumn{3}{|c|}{0.93} \\
\hline
\end{tabular}

Table 3: Genotype frequency and allelic frequencies of $\mathrm{P} 12 \mathrm{~A}$ polymorphism in Controls and IPAH group.

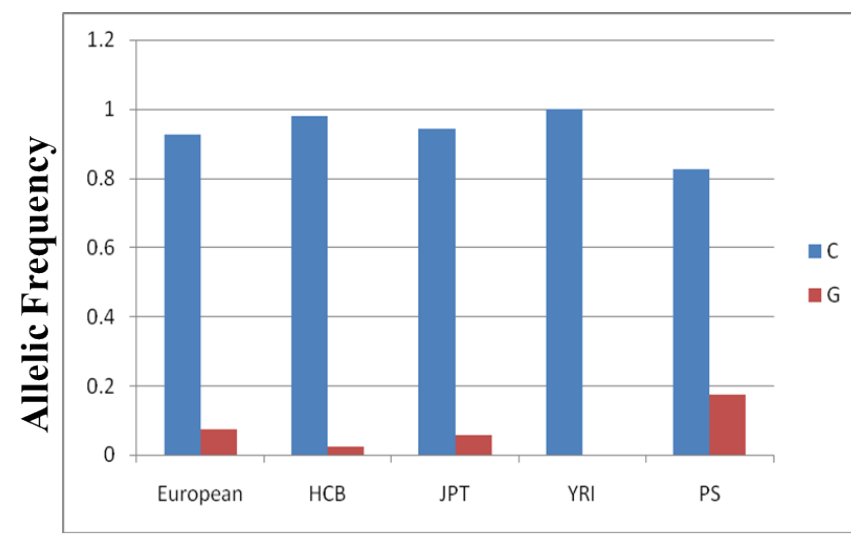

Populations

Figure 4: Comparison of Allelic Frequency of P12A polymorphism with the HapMap Data.

\begin{tabular}{|l|c|c|c|c|}
\hline Genotype & Controls & IPAH & OR $(95 \% \mathrm{Cl})$ & $\mathrm{P}$ \\
\hline CC vs. CG & 27 & 11 & $0.42(0.19-0.91)$ & $\mathbf{0 . 0 0 7 4}^{*}$ \\
\hline CC vs. GG & 4 & 0 & 0 & \\
\hline CC vs. CG/GG & 31 & 11 & $0.37(0.17-0.79)$ & $\mathbf{0 . 0 0 7 2}^{*}$ \\
\hline CC/CG vs. GG & 4 & 0 & 0 & 0.3 \\
\hline
\end{tabular}

OR: Odds Ratio, Cl: Confidence Intervals, * $\mathrm{p}<0.05$

Table 4: Odds test of association of $\mathrm{P} 12 \mathrm{~A}$ polymorphism with IPAH. 
With respect to the WHO functional class, mean age at onset and RVSP levels, comparison among the CC and CG genotypes revealed no significant variation. But, the patients with Alanine variant showed almost a decade early age at onset $(17.54 \pm 6.59)$ of the disease than the patients homozygous for proline variant $(25.52 \pm 11.5)$.

Comparison of symptoms among patients with CC genotype and CG genotype revealed increased frequency of Palpitations $(69.2 \%$ vs. $58.3 \%)$, presyncope (60\% vs. $33.3 \%)$ and paroxymal nocturnal dyspnea $27.7 \%$ vs. $8.3 \%$ ) in the patients with CC genotypes. The frequency of PND and presyncope was three and two folds higher, respectively in patients with CC genotypes.

\section{Discussion}

Prostacyclin has been recognized as a therapeutic target in treatment of IPAH culminating in improved survival via sustained clinical and haemodynamic improvement [28]. Reduced expression of PGIS, has been demonstrated in the lung tissue sample of IPAH patients [29]. The $9 \mathrm{bp}$ VNTR in the 5'-flanking region of PGIS, is known to significantly affect its promoter activity on IL-6 stimulation. The number of Sp1consensus-sequence motifs in the VNTR polymorphism determines the promoter activity, with highest promoter activity observed in the R6 allele containing five Sp1-binding sites [26,30]. However, in the present study no significant difference in the distribution of VNTR alleles in IPAH group was observed, suggesting that this polymorphism may not play any role in reduced expression and levels of PGI2 in IPAH. In contrast, Nana-Sinkam et al [9] reported that the allele containing five Sp1-binding sites has least promoter activity and reported an increased frequency of this allele in PAH patients with known BMPR2 mutations suggesting a potential functional role for the promoter polymorphism in the pathogenesis of IPAH. The frequency of the VNTR promoter polymorphism is known to be influenced by ethnicity and hence could account for contrasting results obtained in Indian and Caucasian IPAH patients.

Hypermethylation of CpG dinucleotides found within the PGIS promoter is associated with reduced PGIS expression. CpG methylation provides an epigenetic mechanism for the down-regulation of PGIS expression and is implicated in lung and colorectal cancers [31]. Hence similar epigenetic mechanism may account for reduced PGIS expression and subsequently low PGI2 levels in IPAH. It has been suggested that an individual's PGIS allelotype is crucial in determining PGIS expression for the presence of even one "short" VNTR allele (S, three and four repeats) is associated with significantly less 6-keto-PGF1a in urine, suggesting lower PGIS expression from PGIS promoters with a low number of VNTRs [29,31].

A novel non-synonymous polymorphism was observed in the study cohort that results in substitution of Arginine with Leucine (R275L) in exon 6 of PGIS. Difference in the presentation of symptoms of angina and presyncope were observed in patients based on this polymorphism. Interestingly, no homozygotes (L275L) were observed either in patients or controls indicating the unique gene pool of Indian origin. The effect of the R275L amino acid substitution on the catalytic activity of PGIS requires further evaluation, especially in view of various physiological roles of PGIS, together with its implication in human diseases.

Reduced levels of PGIS and PGI2 in IPAH may not be a result of genetic variations in PGIS, but may be due to other factors which influence its expression. Studies have also shown that peroxynitrite preferentially inactivates PGIS by heme-thiolate-catalyzed tyrosine nitration which results in reduced production of $\mathrm{PGI}_{2}$ and increased formation of vasoconstrictor prostanoids [32]. Hence increased oxidative stress may result in tyrosine nitration of PGIS by peroxynitrite, accounting for reduced PGIS expression and low levels of PGI2 in IPAH.

A reduced expression of PPAR $\gamma$ gene and protein has been observed in the lungs from patients with severe $\mathrm{PAH}$, with complete loss of PPAR $\gamma$ expression in the plexiform lesions [17]. The transcription factor PPAR $\gamma$ and its putative target apoE are potential downstream effectors of BMPR-2 signalling. The mRNA expression of both factors and BMPR-2, is decreased in lung tissues from PAH patients [33,34]. It is also known that PPAR $\gamma$ activation inhibits the TGF $\beta$ signal pathway in VSMC [35].

In the present study, a high frequency of the IR risk conferring P12P genotype was observed in IPAH patients, which was found to be significantly associated with the disease. The patients with $\mathrm{P} 12 \mathrm{P}$ genotype also had higher frequency of PND, a symptom associated with disease severity and bad prognosis but not with WHO Functional Class or RVSP levels. Thus the P12 P genotype may be a modifier allele in PAH in conjunction with BMPR-2 and apoE involved in the pathway. It is therefore possible that certain kinds of diet can be important triggers for onset of PAH as diet seems to influence PPAR $\gamma 2$.

The P12A variants of the PPAR- $\gamma 2$ were shown to cause a different drug efficacy in vitro [36]. Therefore it has been postulated that the P12A variant of the PPAR- $\gamma$ gene could cause differences in the efficiency of TZD therapy in clinical application and may be useful in assessment of good responders from non-responders to TZD treatment.

$\mathrm{PGI}_{2}$ and its analogues are ligands for peroxisomal proliferatoractivated receptors, and also selectively increase PPAR $\gamma$ activity both in non-transformed epithelial cells and in non-small-cell lung cancer. In human lung cancer cell lines, activation of PPAR $\gamma$ by pharmacologic agents or by molecular overexpression strongly inhibits transformed growth $[25,37,38]$. This may also occur in the epithelial cells of the lung, which are under attack in IPAH, i.e. an increased expression of prostacyclin via its VNTR controlled promoter may lead to an increase in PPAR $\gamma$ activity. Thus, $\mathrm{PGI}_{2}$ and PPAR $\gamma$ may act as therapeutic targets for IPAH in conjunction.

In the present study, the alanine variant was found to be significantly associated with a reduced risk of IPAH. Interestingly none of the patients were found to be homozygous for the Alanine variant. However, the patients with alanine variant had an early age at onset of disease than their P12 P counterparts. This could be because of very low frequency of heterozygotes and complete absence of A12A homozygotes in the IPAH group. Hence, studies with larger patient cohort are necessary for determining the exact role of this polymorphism in IPAH.

\section{Conclusion}

This study has attempted to correlate promoter/gene polymorphisms of PGIS to its activity, and it can be concluded that the VNTR polymorphism and the polymorphism found in exon 6 may not have an effect on the levels of PGIS, with a possible explanation being ethnicity of the cohort studied.

Taking into account the possibility of IR being a risk factor in IPAH, the P12A polymorphism in PPAR $y$ was studied. In the present study, the alanine variant was found to be significantly associated with a reduced risk of IPAH. This could be because of very low frequency of heterozygotes and complete absence of A12A homozygotes in the IPAH group. Hence, studies with larger patient cohort are necessary for determining the exact role of this polymorphism in IPAH. 
Citation: Vadapalli S, Chaitra KL, Satyanarayana ML, Surekha Rani H, Sastry BKS, et al. (2015) Variants of PGIS and PPARy in Idiopathic Pulmonary Arterial Hypertension. J Clin Med Genomics 3: 130. doi: 10.4172/2472-128X.1000130

\section{Acknowledgements}

SRF from ICMR and financial support from PVRI-GSK, UK is duly acknowledged.

\section{References}

1. Simonneau G, Robbins IM, Beghetti M, Channick RN, Delcroix M, et al. (2009) Updated clinical classification of pulmonary hypertension. J Am Coll Cardiol 54: S43-54.

2. Galie N, Hoeper MM, Humbert M, Torbicki A, Vachiery JL, et al. (2009) Guidelines for the diagnosis and treatment of pulmonary hypertension: the task force for the diagnosis and treatment of pulmonary hypertension of the European Society of Cardiology (ESC) and the European Respiratory Society (ERS), endorsed by the International Society of Heart and Lung Transplantation (ISHLT). Eur. Heart J 30: 2493-2537.

3. Runo JR, Loyd JE (2003) Primary pulmonary hypertension. Lancet 361: 15331544.

4. Moncada S, Gryglewski R, Bunting S, Vane JR (1976) An enzyme isolated from arteries transforms prostaglandin endoperoxides to an unstable substance that inhibits platelet aggregation. Nature 263: 663-665.

5. Vane JR, Botting RM (1995) Pharmacodynamic profile of prostacyclin. J Cardio 75: 3A-10A.

6. Graf $\mathrm{H}$ (1993) Endothelial control of cell migration and proliferation. Eur Heart J 14 Suppl I: 183-186.

7. Groves BM, Rubin LJ, Frosolono MF, Cato AE, Reeves JT (1985) A comparison of the acute hemodynamic effects of prostacyclin and hydralazine in primary pulmonary hypertension. Am Heart J 110: 1200-1204

8. Palevsky H, Long W, Crow J, Fishman AP (1990) Prostacyclin and acetylcholine as screening agents for acute pulmonary vasodilator responsiveness in primary pulmonary hypertension. Circulation 82: 2018-2026.

9. Patrick Nana-Sinkam, Ryan J Oyer, RS Stearman, Sylk Sotto-Santiago, Mark D Moore, et al. (2005) Prostacyclin Synthase Promoter Regulation and Familia Pulmonary Arterial Hypertension Chest 128: 612S

10. Mukherjee R, Jow L, Croston GE, Paterniti JR Jr (1997) Identification, characterization, and tissue distribution of human peroxisome proliferatoractivated receptor (PPAR) isoforms PPAR 2 versus PPAR 1 and activation with retinoid X receptor agonist and antagonists. J Biol Chem 272: 8071-8076.

11. Kliewer SA, Umesono K, Noonan DJ, Heyman RA, Evans RM (1992) Convergence of 9 -cis retinoic acid and peroxisome proliferator signalling pathways through heterodimer formation of their receptors. Nature 358: 771 774.

12. Von Knethen AA, Brüne B (2001) Delayed activation of PPARgamma by LPS and IFN-gamma attenuates the oxidative burst in macrophages. FASEB J 15: $535-544$

13. Sarraf P, Mueller E, Smith WM, Wright HM, Kum JB, et al. (1999) Loss-offunction mutations in PPAR gamma associated with human colon cancer. Mol Cell 3: 799-804.

14. Xin X, Yang S, Kowalski J, Gerritsen ME (1999) Peroxisome proliferatoractivated receptor gamma ligands are potent inhibitors of angiogenesis in vitro and in vivo. J Biol Chem 274: 9116-9121.

15. Chinetti G, Griglio S, Antonucci M, Torra IP, Delerive P, et al. (1998) Activation of proliferator-activated receptors alpha and gamma induces apoptosis of human monocyte-derived macrophages. J Biol Chem 273: 25573-25580.

16. Fuenzalida K, Quintanilla R, Ramos P, Piderit D, Fuentealba RA, et al. (2007) Peroxisome Proliferator-activated Receptor ? Up-regulates the Bcl-2 Antiapoptotic Protein in Neurons and Induces Mitochondrial Stabilization and Protection against Oxidative Stress and Apoptosis. J Biol Chem 282: 37006-15.

17. Ameshima S, Golpon H, Cool CD, Chan D, Vandivier RW, et al. (2003) Peroxisome proliferator-activated receptor gamma (PPARgamma) expression is decreased in pulmonary hypertension and affects endothelial cell growth. Circ Res 92: 1162-1169.

18. Combs CK, Johnson DE, Karlo JC, Cannady SB, Landreth GE (2000) Inflammatory mechanisms in Alzheimer's disease: inhibition of beta-amyloidstimulated pro-inflammatory responses and neurotoxicity by PPARgamma agonists. J Neurosci 20: 558-567.

19. Imaizumi T, Matsumiya T, Tamo W, Shibata T, Fujimoto K, et al. (2002)
15-Deoxy-D12,14-prostaglandin J2 inhibits CX3CL1/fractalkine expression in human endothelial cells. Immunol Cell Biol 80: 531-536.

20. Ikeda Y, Yonemitsu Y, Kataoka C, Kitamoto S, Yamaoka T, et al. (2002) Antimonocyte chemoattractant protein-1 gene therapy attenuates pulmonary hypertension in rats. Am J Physiol Heart Circ Physiol 283: H2021-H2028.

21. Martin-Nizard F, Furman C, Delerive P, Kandoussi A, Fruchart JC, et al. (2002) Peroxisome proliferator-activated receptor activators inhibit oxidized low-density lipoprotein-induced endothelin-1 secretion in endothelial cells. J Cardiovasc Pharmacol 40: 822-831.

22. Lehrke M, Lazar MA (2005) The many faces of PPARgamma. Cell 123: 993999.

23. Deeb SS, Fajas L, Nemoto M, Pihlajamäki J, Mykkänen L, et al. (1998) A Pro12Ala substitution in PPARgamma2 associated with decreased receptor activity, lower body mass index and improved insulin sensitivity. Nat Genet 20 : 284-287.

24. Sokkar S, El-Sharnouby JA, Helmy A, El-Bendary A, Ahmad LS, et al. (2009) Role of Peroxisome Proliferator- Activated Receptor gamma2 Gene Polymorphism in Type 2 Diabetes Mellitus Eur J Gen Med 6: 78-86.

25. Forman BM, Chen J, Evans RM (1997) Hypolipidemic drugs, polyunsaturated fatty acids, and eicosanoids are ligands for peroxisome proliferator-activated receptors alpha and delta. Proc Natl Acad Sci U S A 94: 4312-4317.

26. Chevalier D, Cauffiez C, Bernard C, Lo-Guidice JM, Allorge D, et al. (2001) Characterization of new mutations in the coding sequence and 5'-untranslated region of the human prostacylcin synthase gene (CYP8A1). Hum Genet 108: $148-155$

27. Orita M, Iwahana H, Kanazawa H, Hayashi K, Sekiya T (1989) Detection of polymorphisms of human DNA by gel electrophoresis as single-strand conformation polymorphisms. Proc Natl Acad Sci U S A 86: 2766-2770.

28. Barst RJ, Rubin LJ, Long WA (1996) A comparison of continuous intravenous epoprostenol (prostacyclin) with conventional therapy for primary pulmonary hypertension. N Engl J Med 334: 296-302

29. Tuder RM, Voelkel NF (1998) Pulmonary hypertension and inflammation. J Lab Clin Med 132: 16-24.

30. Iwai N, Katsuya T, Ishikawa K, Mannami T, Ogata J, et al. (1999) Human prostacyclin synthase gene and hypertension : the Suita Study. Circulation 100: 2231-2236

31. Stearman RS, Grady MC, Nana-Sinkam P, Varella-Garcia M, Geraci MW (2007) Genetic and epigenetic regulation of the human prostacyclin synthase promoter in lung cancer cell lines. Mol Cancer Res 5: 295-308.

32. Zou MH, Daiber A, Peterson JA, Shoun H, Ullrich V (2000) Rapid reaction of peroxynitrite with heme-thiolate proteins as the basis for protection of prostacyclin synthase from inactivation by nitration. Arch Biochem Biophys 376: 149-155

33. Geraci MW, Gao B, Shepherd DC, Moore MD, Westcott JY, et al. (1999) Pulmonary prostacyclin synthase overexpression in transgenic mice protects against development of hypoxic pulmonary hypertension. J Clin Invest 103 $1509-1515$

34. Atkins KB, Northcott CA, Watts SW, Brosius FC (2005) Effects of PPAR-gamma ligands on vascular smooth muscle marker expression in hypertensive and normal arteries. Am J Physiol Heart Circ Physiol 288: H235-243.

35. Han J, Hajjar DP, Tauras JM, Feng J, Gotto Jr AM, et al. (2000) Transforming growth factor-b1 (TGF-b1) and TGF-b2 decrease expression of CD36, the type $\mathrm{B}$ scavenger receptor, through mitogen-activated protein kinase phosphorylation of peroxisome proliferator-activated receptor-c. J. Biol. Chem 275: $1241-1246$

36. Masugi J, Tamori Y, Mori H, Koike T, Kasuga M (2000) Inhibitory effect of a proline-to-alanine substitution at codon 12 of peroxisome proliferator-activated receptor-gamma 2 on thiazolidinedione-induced adipogenesis. Biochem Biophys Res Commun 268: 178-182

37. Bren-Mattison Y, Van Putten V, Chan D, Winn R, Geraci MW, et al. (2005) Peroxisome proliferator-activated receptor-? (PPAR(?)) inhibits tumorigenesis by reversing the undifferentiated phenotype of metastatic non-small-cell lung cancer cells (NSCLC). Oncogene 24: 1412-1422.

38. Wick M, Hurteau G, Dessev C (2002) Peroxisome proliferator-activated receptor-? Is a target of nonsteroidal anti-inflammatory drugs mediating cyclooxygenase-independent inhibition of lung cancer cell growth. Mol Pharmacol 62: 1207-1214. 